


\title{
Poesía y Música: correspondencias y despliegue expresivo en la poesía nicaragüense del siglo xx: Pallais, Cardenal y Téllez ${ }^{1}$
}

\author{
Etry and Music: correspondences and expressive deployment in the nicaraguan poetry in the \\ twentieth century: Pallais, Cardenal and Téllez \\ Jorge Chen Sham² \\ Recibido: 25/8/2016 / Aprobado:1/11/2016
}

\begin{abstract}
Resumen
Las relaciones entre Poesía y Música están en el origen mismo de la conformación del género de la lírica. El carácter delectable y los efectos sugestivos del lenguaje en la asociación entre belleza y ornamentación de la palabra dan paso a relaciones de correspondencia, cuando la Poesía plantea relaciones intertextuales o intersemióticas con la música. Desde las teorías estéticas del Romanticismo, estas correspondencias conducen a la teoría expresiva del lenguaje poético y, para ello, el poeta debe privilegiar el proceso psicológico-perceptivo, cuando la música se convierte en forma "simbólica" y "trascendente", tanto el énfasis en el efecto compositivo-estructural así como en la estructura del poema, con el fin de que las correspondencias sean palpables y analizables. El corpus del artículo es Azarías H. Pallais y su libro Caminos (1925), en donde la sección "Los caminos del crepúsculo" retoma la oración del ángelus desde el ritual de las vísperas con el canto gregoriano; Ernesto Cardenal y sus Salmos (1964), específicamente el "Salmo 150", que cierra con explosión musical y cósmica, al remitir al finale de la Quinta Sinfonía de Beethoven; y Fánor Téllez, con su poemario Oficio de amarte (1999), en donde realiza un elogio y una alabanza al trovador y a su concepción de la lira amatoria en "La canción por ti encendida".
\end{abstract}

Palabras clave: : poesía nicaragüense, relaciones y correspondencias entre poesía y música, Azarías H. Pallais, Ernesto Cardenal y Fánor Téllez.

\section{Abstract}

The relationships between poetry and music are in the same origin of the lyric gender conformation. The detectable character and the language suggestive effects in the association of the beauty and ornamentation The relationships between poetry and music are in the same origin of the lyric gender conformation. The detectable character and the language suggestive effects in the association of the beauty and ornamentation of the word, it opens to a correspondence when poetry approaches intertextual or intersemiotic relationships with the music. From Romanticism esthetic theories, they lead to an expressive theory of the poetic language, for that, the poet should give privilege to the psychological-perceptive process, when the music becomes symbolic and transcendent in as much as in the emphasis of compositional-structural effect along with the poem structure, with the purpose that the correspondences are palpable and analyzable. The corpus will be as follows: Azarías H. Pallais y su libro Caminos (1925), where the section "Los caminos del crepúsculo", retake the `Angelus` from the ritual eve of Gregorian singing; Ernesto Cardenal y sus Salmos (1964), specifically "Salmo 150", that closes with musical and cosmic explosion forwarding to Beethoven's Fifth Symphony; and Fánor Téllez with his poem 'Oficio de amarte' (1999), where he makes a praise and tribute to a troubadour and his conception of the lira amatory in "La canción por ti encendida".

Key Words: Nicaraguan poetry, relations and correspondences between poetry and music, Azarías H. Pallais, Ernesto Cardenal and Fánor Téllez.

\footnotetext{
${ }^{1}$ Este texto corresponde con la temática de la ponencia presentada en el II Coloquio Internacional de Investigación y Creación de la Cultura Artística Centroamericana, realizado el 9, 10 y 11 de setiembre de 2015, en el Museo Regional de San Ramón y en la Sede de Occidente, Universidad de Costa Rica, ahora en formato de artículo científico, en versión completa extendida. ${ }^{2}$ Profesor y Doctor en Estudios Románicos, Université Paul Valéry, Montpellier III, Francia.

Profesor catedrático de la Escuela de Filología, Lingüística y Literatura de la Universidad de Costa. Correo electrónico:jorgechsh@ yahoo.co
} 


\section{Introducción}

Las relaciones entre la literatura y la música tienen una larga tradición en la literatura occidental y ha recibido también un extenso análisis desde Platón y Aristóteles. En el pensamiento griego, la mímesis literaria en cuanto Tekjné se emparentaba con las otras artes por su carácter delectable y por sus efectos sugestivos del lenguaje. La asociación de la palabra poética con la música se encuentra en el origen mismo de la poesía, en cuanto a que el ritmo y el metro despliegan el recurso de la armonía fundante del verso, porque de lo que se trata es de la inspiración. Se aleja del cliché que asocia lo poético con la belleza y la ornamentación de las palabras, porque su significación auténtica radica en su origen trascendental en la dicotomía razón-locura. Remite a Platón en su diálogo Ion o De la Poesía, en donde se plantea la raigambre divina de la Poesía y la asocia al delirium tremens, a esa manifestación de lo sagrado. La divinidad, por medio de las Musas, se posesiona del alma del poeta y se inspira; dice Sócrates a Ion en este sentido:

Es así como la Musa en persona produce algunos endiosados y, a través de estos, otros se entusiasman y trabajan en cadena. Pues todos los poetas épicos, los buenos, no dicen por arte sus bellos poemas, sino por endiosados y posesos. Igualmente los buenos poetas líricos. Así como los coribantes no están en sus cabales cuando bailan, tampoco los poetas líricos cuando componen sus bellos cantos. Apenas pisan la armonía y el ritmo caen en trance báquico y quedan posesos [...]. (1974: 33)

El acto poético pretende aquí la interpelación de esas fuerzas motoras del universo $y$, al demostrar que la Poesía no es de factura humana porque se nutre de una posesión (delirio) que lo arrastra y lo saca de sí mismo, Platón subraya el origen divino y transcendental de la inspiración poética, razón por la cual no puede explicarse bajo leyes humanas o conceptos de verdad. El poeta es un iluminado y un enardecido por una energía vital y, al ser instrumentos de los dioses, está en la misma categoría que otros tipos de poseídos (o inspirados), como recuerda Roberto Cañas: "La poesía es el efecto de una posesión divina semejante al frenesí de los sacerdotes y profetas" (1995: 82). Por esa razón, Platón reivindica la locura, ese salirse de sí mismo para asumir el daimon de la creación. Así, desenfreno y locura se dan la mano y promueven tanto el enardecimiento del espíritu como una energía liberadora ${ }^{3}$, a través de una posesión que Platón vuelve a atribuir a las Musas en el Fedro o De la Belleza; tratado en donde diferencia la posesión del poeta de otros tipos, tales como la proféticoadivinatoria o la ritual-religiosa. Platón explica que un extraño impulso mueve a que la Musa "inspira odas y otros poemas" (2004: 132) y lo primero que subraya es la melodía sugestiva, la voz, la declamación para subrayar, al fin y al cabo en Ion o De la Poesía, la respuesta corporal y anímica de Ion cuando oye los versos de Homero y los puede interpretar, es decir, ejecutar: " $y$, apenas suenan cantos de tu poeta, despiertas de golpe, te baila el alma y hablas con soltura" (1974: 36). Esta energía tiene que resonar a través del rapsoda, porque la voz y el canto deben surgir acompañados de la música y la danza. He aquí cómo se despliega, entonces, la preeminencia de la melodía y la eufonía para irradiar ese magnetismo de la inspiración poética.

\section{La teoría expresiva de la Poesía y el papel del poeta}

Estas ideas vuelven a encontrarse en los desarrollos estéticos del Romanticismo, a finales del siglo XVIII. En tanto estética renovadora y gran revolución en el plano de la Modernidad filosófica del siglo XVIII, el Romanticismo tendría el mérito de ser el gran catalizador de esa ruptura coloca la conciencia individual y la imaginación acendrada en un primer plano de esos debates que, en política, se plantean la condición de la libertad humana y

\footnotetext{
${ }^{3}$ Y si se sabe leer el texto de Platón, también libidinal. Por otra parte, Cañas recuerda que el término en griego clásico que corresponde a la locura es uavıa (manía), pero se trata de una posesión en tanto don que proviene de los dioses (Cañas, 1995: 83).
} 
asientan los pilares de las grandes reformas sociales del siglo XIX. Es renovadora, en primer lugar, porque se aleja de una noción mimética del arte, que la hacía un espejo de la naturaleza a la cual debía "imitar". Desde esta concepción clásicohoraciana se infería la necesidad de que el prodesse (la enseñanza) y el delectare (el deleite) debían estar en justo equilibrio para que el fin supremo de la poesía se consiguiera, lo cual dejaba en una posición inferior a esos medios a los que el movere (la emoción) apelaba; sin embargo, el planteamiento de las tres funciones (delectare, prodesse y movere) resumirá "la suma de los efectos estéticos del arte sobre el lector" (Abrams, s.f.: 30).

Dos grandes posiciones se expondrán a lo largo del Antiguo Régimen: los que encuentran que el efecto moral debía ser el objetivo supremo (prodesse), o los que consideraban que el arte debía reducirse solamente a efectos melodioso-sugestivos del placer (delectare). La novedad, presentada a principios del siglo XIX sobre todo en Inglaterra y en Alemania, es radical y se resume con el nombre de teoría expresiva del arte, pues agregarán a la consideración de las tres funciones estéticas la preocupación por el papel del "creador" y por el paralelismo intrínseco reunido en la obra y al poeta en una misma consonancia y equilibrio de energías:

La poesía es el desborde, exteriorización o proyección del pensamiento y sentimientos del poeta; o dicho de otro modo (en la principal de las variantes de esa formulación) la poesía es definida por referencia al proceso imaginativo que modifica y sintetiza las imágenes, pensamientos y sentimientos del poeta. A este modo de pensar, en que el artista se convierte en el elemento principal tanto del producto artístico como de los criterios conforme a los cuales ha de ser juzgado, lo llamaré teoría expresiva del arte. (Abrams, s.f.: 38$)$

No es que sea nuevo en este contexto el referirse a la imaginación o a las emociones del artista, sino que se parte aquí de esa analogía entre los procesos de creación y la mente humana; carga, entonces, su acento sobre la primacía de la conciencia integradora del escritor y sobre el privilegio de proceso psicológico-perceptivo que lo muestran como un ser excepcional y genial, como corolario a esa atención puesta a la visión onírica y a lo que ocurre en las etapas de vigilia (Béguin, 1993: 27-32). El proceso creador atiende los estados anímicos del artista y su dinámica se plantea en términos de un "desborde" de un acto interior (Abrams, s.f.: 74), por lo que es expresión de lo que se ocurre en el interior del espíritu del poeta:

Repetidamente los predicados románticos acerca de la poesía o sobre el arte en general giran sobre una metáfora que, como la del "desborde", significa lo interno que se hace externo. El más frecuente de esos términos fue 'expresión', empleado en contextos que indicaban un revivir del significado de la raíz ex-pressus, de ex-premere, "apretar hacia afuera”. Como escribía A. W. Schlegel en 1801 [se trata de sus Prolegómenos a la Literatura y las Bellas Artes], refiriéndose a los signos vocales del sentimiento, la "palabra expresión (Ausdruck) ha sido elegida muy llamativamente por esto: lo interno es expulsado hacia fuera como por una fuerza ajena a nosotros". (Abrams, s.f.: 74, las cursivas son del texto)

De esta manera, la teoría expresiva nos conduce a unos planteamientos que sopesan al mismo tiempo las causas instrumental y eficiente de la poesía. Recordemos con Antonio García Berrio que desde la teoría horaciana, la literatura viene circunscribiéndose a tres causas que la explican: la causa final, ¿cuál es la finalidad de la literatura, la enseñanza o el deleite?; la causa instrumental, ¿cuáles son los instrumentos o medios para alcanzar tal finalidad?, los medios serían el lenguaje o la efectividad ese lenguaje lograda en la relación entre verba (palabras) y res (contenido); y la causa eficiente, ¿cuál concepción del talante o la función del poeta que se infiere de esta finalidad y cómo se valora el proceso creador?, ¿es el creador báquicopasional o apolíneo-reflexivo? (García Berrio, 1973: 
25-26). De manera que el Romanticismo y, con esta corriente luego el posterior paradigma formalista, privilegiará la causa instrumental subrayando la primacía del lenguaje poético y reafirmando su valor motivado, de lenguaje de equivalencias y de correspondencias, las cuales deben suscitar un reconocimiento y una identificación (Schaeffer, 1980: 186).

\section{El lenguaje poético-musical y la valoración de las emociones}

La valoración del lenguaje poético y la Música se justifica en dos razones. En primer lugar, se le consideró como el arte más alejado de la función mimética que ni duplica la naturaleza ni es su espejo, pues en los filósofos alemanes del Romanticismo, "la música llegó a ser el arte más inmediatamente expresivo del espíritu y la emoción" (Abrams, s.f.: 78). Por lo tanto, como su mensaje es opaco y necesita de una interpretación a partir de aquello que sugiere, es más apropiada para el sentimiento, arguyen los filósofos románticos (Abrams, s.f.: 141). En segundo lugar, en su correspondencia entre las palabras y la música melodiosa se valora la causa instrumental, al destacar el medio empleado (las palabras) y, en este sentido, su relación con las nociones platónicas del "dulce deleitar", propio de la tradición de lo melífico en el pensamiento literario de la Antigüedad, tal y como exponía Platón en Ion: "Pues los poetas nos dicen, ¿no es cierto?, que voladores como abejas nos traen sus bellos cantos que han libado de fuentes de miel de los ríos" (1974: 33).

Sin embargo, el Romanticismo alemán lleva al mismo grado de perfección a la Música y a la Poesía, con la mezcla de procedimientos y recursos a los que debía aspirar la composición poética; desde la armonía cromática a la fragancia musical o a la melodía de imágenes, la música impregna la teoría estética para que sea "expresión pura [...] del espíritu y de los sentimientos" (Abrams, s.f.: 142). Por ello, no es de extrañar que el Romanticismo sancione el estatuto y esta correspondencia, de Música y Poesía, con analogías en la interacción del enlace entre lo interno y externo del proceso creador, por cuanto el poeta desea develar los misterios del cosmos, ese lenguaje musical de la naturaleza. Para A. W. Schlegel, en su Curso de literatura dramática, la inteligencia únicamente puede captar la verdad de una cosa solamente en forma fragmentaria, "el sentimiento, en cambio, al abarcar todas las cosas, lo comprende todo y en todo penetra" (citado por Aguiar e Silva, 1979: 328).

De esta manera, esa música espiritual, la música del universo que ofrece sus claves para quien quiera escucharlas, se revela en el corazón del poeta. La vinculación de la música y las pasiones se establece para quien pueda ahondar en los secretos del alma (Abrams, s.f.: 79), lo cual conduce a subrayar no solo esa capacidad del creador para expresar las emociones (lo que la estilística llamará la intuición del poeta), sino también el medio utilizado para exteriorizarlas: la palabra delicada, melodiosa, atemperada por un lado; apasionada, revoltosa, brillante y encendida, por otro, con el fin de expresar la gama que va desde la exaltación hasta la calma reflexiva ${ }^{4}$. A la luz de lo anterior, el tono del sentimiento debe expresarse con todos los recursos y medios del lenguaje (Abrams, s.f.: 137), lo cual conducirá, en las teorías formalistas herederas del Romanticismo, a "la exaltación de la forma [...], articulador de todo su sistema, de la teoría moderna del arte" (García Berrio, 1973: 29). La primacía de las emociones tiene su correspondencia en el proceso creativo de la música, el cual sugiere y provoca a partir de los sonidos y de su ritmo. Así sucede también con el lenguaje poético, capaz de incorporar "objetos del mundo de los sentidos que ya han sido influidos y transformados por los sentimientos del poeta" (Abrams, s.f.: 82). Se pondera el valor de la introspección imaginativa e integradora del artista; los sentimientos (las pasiones) permean y proyectan su ángulo sobre las cosas que mira el poeta y les proporciona el lente especial desde el cual la euforia o la disforia contaminan tanto la percepción como la imaginación.

\footnotetext{
${ }^{4}$ Aquí valen todas esas expresiones que utilizará el compositor como ayuda de memoria a la partitura: vivace, moderato, allegro, andante, con fuoco, etc.
} 
Ahora bien, desde el clásico Ut Pictura Poesis, que la tradición griega aprehende como esa manera de transponer los sentidos y conseguir un lenguaje poético transformado en pintura verbal, también los poetas han intentado acercar la Poesía a la representación escultórica y arquitectónica, entre otras artes (Welleck y Warren, 1979: 150), pero priva fundamentalmente la musical. Esta interdependencia es posible por el despliegue de sensaciones auditivas que se convocan para que la palabra poética sea moldeada y transfigurada por la referencia musical, para componer una pieza musical o para que la correspondencia eufónica de la melodía musical permita configurar, lo que da la proporción, medida y el volumen que las estructuras de la rima o la medida de versos y de estrofas permitían tradicionalmente. Pero no se trata de privilegiar solamente estas equivalencias rítmico-eufónicas de efectos sonoros, aunque son importantes.

Si el poeta puede trabajar la palabra para componer una antífona del oficio litúrgico en latín, una sinfonía o himno de alabanza universal a semejanza de los románticos alemanes, ya sea una canción con el embelesamiento de los trovadores medievales, es porque también apelan a la "cualidad fónica": "el tono, la duración de los sonidos, el acento, la frecuencia de repetición, [son] elementos todos que permiten distinciones cuantitativas: el tono es más alto o más bajo, mayor o menor la duración, más fuerte o más débil el acento, mayor o menor la frecuencia de repetición" (Wellek y Warren, 1979: 188), pero aquí el poeta apela a otra evocación de la composición musical en su referencia cualitativa a la creación de un entorno musical que haga surgir referencias culturales y relaciones intersemióticas, es decir, entre diferentes artes.

No se está planteando tanto una adecuación de lo poético a la música como si fuera una simple transposición artística, ni tampoco como una simple relación intertextual en el caso de un texto literario se asocie a otra obra artística identificable; todo lo contrario, el interés radica en el grado de representación musical que el texto poético suscita o proyecta, el cual depende del régimen de descodificación que, por medio de los sentidos y de las imágenes forjadas, evidencie. Por ello, la constitución y la estructura interna del texto poético así construido remite a una forma dinámica en el sentido de que "más que en la arquitectura los diferentes materiales empleados, en la [literatura] lo estructurado, lo construido, lo formado interviene cualitativamente en la forma, en la construcción, en la estructura misma" (Alonso, 1969: 90). ${ }^{5}$ Los ejemplos por analizar pertenecen a un corpus de poesía nicaragüense del siglo XX; cubren tres momentos diferentes del canon poético de ese país que ha aportado tanto al desarrollo de este género desde la impronta de Darío y el Modernismo. Su elección no significa que esta poesía tenga una propensión por sus correspondencias con la música antigua y clásica; solamente representa el interés por establecer relaciones entre artes que desde la Antigüedad se influyen mutuamente; relación a la que vuelven estos poetas.

\section{Las antífonas del oficio litúrgico y el canto gregoriano: Azarías H. Pallais}

El nicaragüense Azarías H. Pallais (18841954) publicó ese poemario ejemplar que es Caminos en 1925. En este poemario, construido a partir de dísticos alejandrinos, Pallais utiliza una estructura temporal que transforma la celebración litúrgica de las Horas dentro de una arquitectura poética inconfundible y un sentido ideológico bien delimitado. El tiempo de la salvación, es decir, el tiempo kairológico cristiano, impone que ese momento justo y decisivo para ser humano desemboque en la posibilidad de la redención, con lo cual se revela el trasfondo de todo proceso temporal (Kerkhoff, 1997: 9-10). Así, la Liturgia de las Horas establece esa direccionalidad a un

\footnotetext{
${ }^{5}$ Ello conduce a Amado Alonso a subrayar que los materiales de una pintura o de un edificio no tienen la misma función que en la poesía, en donde los materiales evocados se emplean dentro de un sistema expresivo, es decir, de construcción por medio de la representación pictórica, arquitectónica o musical.
} 
viaje que realiza el hablante lírico por su acontecer cotidiano, nicaragüense y mundial, y abarca el orbe terrestre en una dimensión de la que no es posible sustraerse fácilmente porque se funda en una de esas metáforas fundantes de Occidente.

Es la noción que ya había expuesto tan acertadamente Dante al principio de La divina comedia: "Nel mezzo del cammin di nostra vita / Mi ritrovai per una selva oscura,/ Chè la diritta via era smarrita" ("Proemio Generale" al "Inferno", "Canto Primo", vv.1-3,1914: 27-28). La existencia se ve aquí como proceso que lleve hacia una meta, con un desarrollo claro y lineal en lo que corresponde a ese conocimiento del ser humano de su verdad. Por eso escoge Pallais ese recorrido temporal que va del amanecer hasta la noche, con el fin de subrayar el camino de aprendizaje de un creyente que encuentra a cada paso y descubre las maravillas de la creación y el poder de la divinidad en la Historia de la humanidad. Para ello, también Pallais selecciona un tipo estrófico de gran tradición y raigambre en la lírica española, como podría ser el dístico alejandrino. Sugiere el trabajo del clásico mester de clerecía, de ese trabajo erudito del clérigo medieval que componía sus poemas religiosos como alabanza a la divinidad, y a pesar de ello y de lo que parecería al lector moderno como una estructura monótona al escoger el dístico con rima pareada, como indica José Argüello Lacayo, "Caminos han resistido las inclemencias del tiempo y conservan aún su frescura, vigor y lirismo.

Si algo veda un tanto su acceso, quizás sea su misma elevación espiritual, pues esta es sin duda la obra poética de un santo" (2004: 11).

Poesía mística y eminentemente religiosa se encuentra en la sección "Los caminos de crepúsculo" toda una serie de símbolos y motivos ligados al atardecer y al tránsito hacia la noche, en una remisión a colores y a la pintura. Reconocer la capacidad del lenguaje poético para permitir experimentar las analogías o las correspondencias entre sonidos y colores en la construcción de un símbolo es lo que acerca el mundo literario de Pallais al simbolismo.
En este sentido, recordemos que, para el simbolismo, la poesía nace de "la íntima experiencia subjetiva y estética del individuo" (Risley, 1992: 56), cuando la percepción/visión del poeta intenta aproximarse al objeto evocado. De esta radical relación surge el poema en tanto símbolo, por lo cual el poeta ni comunica ni describe en tanto haya un símbolo por descifrar para el lector; todo lo contrario, el poema sugiere y evoca una emoción que debe provocar, llamar la atención, sorprender gracias a su construcción expresiva; de ahí la extrañeza/sorpresa para el lector y el contagio que suscita.

La experiencia religiosa queda plasmada en el segundo poema de la sección mencionada anteriormente. La "Mayúscula Segunda", cuyo subtítulo es el siguiente "La divina gracia de las tres avemarías del Ángelus", sugiere el atardecer y el rezo del ángelus. El color elegido por Pallais no es inocente, selecciona el "Oro de los primitivos", en una alusión a la luz del crepúsculo intenso al principio del otoño como a las letras doradas de los incunables que los monjes medievales adornaban. También existe una indicación más al inicio del poema que transmite propiamente el tono lumínico evocado: "MAYÚSCULA SEGUNDA: LOS DULCES LABRADORES $/{ }^{6}$ de Millet riegan sobre sus tareas, las flores".

Remite al famoso cuadro de Millet, cuando los labradores dejan sus labores de segar el trigo para detenerse y orar al caer la tarde, este poema subraya no solo la devoción piadosa de los campesinos, sino también esa pausa que hacen a sus actividades cotidianas para acercarse a la divinidad. Ello obliga a comprender la palabra poética dentro de una experiencia con lo sagrado e inefable, en un intento por sugerir cómo la poesía es esa manifestación de lo sagrado en unión intrínseca al acto de la poesía. La voz poética que se manifiesta en Caminos experimenta esa sensación de profundidad y de vivir un acto extraordinario cada día y, al observar a los campesinos que, "[e]n medio de la tarde rezan las alegrías,/ por la divina gracia de las avemarías" (Pallais, 2004: 109), su espíritu se eleva. La voz

${ }^{6}$ Si no hay indicación alguna, el énfasis es del texto. 
poética se transporta remitiendo a esa liturgia que recuerda las vísperas cantadas en los misales con sus letras en oro, con un tono que comienza alto y se va graduando en la medida en que se los dísticos o pareados se suceden, y se entona el poema gracias a la cesura buscada en dos hemistiquios de igual alternancia:

Mayúscula segunda! En Brujas y en Florencia, todos los primitivos celebran tu inocencia

de letra candorosa, de letra virginal que alumbra con sus oros, la gloria del misal. (Pallais, 2004: 109)

Aquí la rima consonante perfecta va haciendo que la duración sea mayor a final del verso, mientras que la frecuencia de repetición, precisamente de la misma rima, da esa eufonía buscada. La asociación entre color dorado del "misal" y sonido que se modula la voz recuerdan el canto gregoriano, para que se produzca una exaltación de la voluptuosidad formal en esa consideración con lo sublime religioso. De manera que el yo lírico se apresta a vivir lo inefable y hay, en sus palabras, una situación comunicativa que conduce a una concentración de esta experiencia de la alteridad sobre el poeta; la transformación es inmediata e impresionante:

Como la luz soy clara, como el agua soy buena: Así canta mi vida la Gracia Plena

que riegan las campanas: La tarde religiosa eleva sus dos manos, y entonces, mariposa

que vuela dulcemente por todos los caminos, parecen los dos arcos de mis alejandrinos. (Pallais, 2004: 109-110)

Se dibujan aquí dos símbolos conspicuos del cristianismo: la luz y el agua están para marcar la vía unitiva de la experiencia mística gracias a la cual el hablante lírico, absorto, se eleva; la aparición de la sinécdoque "mariposa" connota la imaginación ensoñadora de quien se impulsa por la oración. La acción de elevar "sus dos manos", es decir, del creyente en oración, se convierte en el punto de partida de un acto que ahora "vuela" y manifiesta el don de la ubicuidad. La intensificación del intercambio permite que la poesía, en la metonimia "mis alejandrinos", desborde la oración silenciosa para integrarse en una sumatoria de sensaciones auditivas y cromáticas, en la exaltación de un rezo que se eleva por el cosmos como poesía y como oración. Se llega a un clímax, de enaltecimiento y de unión del oído/vista; todo ello es posible gracias al polisíndeton que implica aquí un crescendo hacia una música celestial, de elevación máxima cuando la música gregoriana transporta con sus "reverberaciones" para que cada palabra surja evanescente en la escala sonora (Les très riches heures du Moyen Age, 1995: 42) ${ }^{7}$ :

Y reza en los colores, el sonido piadoso, y se oye en un equilibrio profundo y milagroso

de luces auditivas y músicas visualesde notas y colores en números iguales. (Pallais, 2004: 110)

El goce y el deleite se apoderan en este entrecruzamiento de imágenes en el que la intensidad del color y la sonoridad de las melodías conducen a una exaltación de las formas artísticas al servicio de un ideal de trascendencia divina. Así, el rezo del ángelus culmina en una celebración exultante de ese sentimiento de comunión y de integración armónica en el dístico "Los cielos y la tierra son una Eucaristía,/ por esta Gracia Plena- flor del Avemaría" (Palais, 2004: 110), para continuar con esa retórica del crepúsculo, en donde la comparación de "la tarde" con "una novia" quien se dirige al altar subraya el movimiento temporal hacia la noche: "La tarde es una novia, pura, dichosa, bella,/ cuando juega en los cielos, como un niño, la estrella" (Palais, 2004: 110). Este momento de gran intensidad es la culminación in decrecendo hacia la noche; la

\footnotetext{
${ }^{7}$ Se cita el folleto introductorio de la coleeción antológica que, con el nombre de Les très riches heures du Moyen Age, dedica el sello discográfico Harmonia Mundi, France, a la música de la Edad Media.
} 
"Mayúscula Segunda" de la sección "Los caminos del crepúsculo" llega a esa síntesis que reenvía de perspectiva en perspectiva al yo poético, bajo un horizonte en el que el mundo se propone como totalidad y apertura (Collot, 1989: 42) y se admira la transición que provoca el crepúsculo: “ $¡ L a$ tierra es un silencio de rama florecida-/ y en los cielos, el canto de la estrella dormida!" (Pallais, 2004: 110). Se trata de un momento de intensificación de los sentidos para subrayar el tránsito del día hacia la noche, tal y como se produce en el poema conclusivo de esta sección, cuyo título es "Entre los caminos de la tarde y los caminos de la noche, el paréntesis de la estrella dormida". Se asocia así al oficio de las vísperas, el canto gregoriano con lo identificado en estos poemas sublima la oración y transporta, como quiere el yo poético, a esos lugares de tradición medieval europea en donde resuenan las notas del canto de los oficios de las vísperas: "En Brujas y en Florencia" (Pallais, 2004: 109), se indicaba.

\section{Una sinfonía de alabanza universal y el allegro apoteósico: Ernesto Cardenal}

Ernesto Cardenal compone lo que muchos han denominado como paráfrasis de los salmos del Antiguo Testamento. Publicados primeramente en la Revista de la Universidad de Antioquia (1964), nunca llegó a hacer versiones de los 150 salmos conocidos. Es significativo que el enfoque cristiano de la salvación, relacionado con el reino de justicia y de liberación, impregne la situación comunicativa del corpus sálmico. No es casual, entonces, que el yo lírico de los Salmos se presente como un sujeto intercesor de una súplica comunitaria de la que él también participa, pues tanto el Psalterio bíblico como el cardenaliano poseen, en común, la característica de ser plegaria y oración "que nos hacen entrar profundamente en la relación entre Dios y el hombre" (Mannati, 1979: 6). Su significación se encuentra, de esta manera, enraizada en el poder de la oración y de la escritura, a las que se le atribuyen esa capacidad de interceder y proteger.

En el Psalterio cardenaliano aparece también la modalidad del himno de alabanza, como acto en el que desemboca su plegaria y su testimonio como creyente. Súplica e himno de gracias son los medios por los cuales "el hombre llega a [Dios] a través de la oración en el recogimiento o a través de la oración en la prueba" (Promis 1975: 23). Sin embargo, uno de los estudiosos de los salmos de Cardenal, José Promis Ojeda, encuentra que la súplica es la única coordenada existente en ellos; no obstante, parece inapropiado afirmar que en ellos se encuentre una supresión de la meditación y de la plegaria de alabanza (de agradecimiento). Promis reconoce la existencia de poemas con estructura de himno de acción de gracias pero están subordinados a la súplica, indica (1975: 21). Ahora bien, existen salmos en el Psalterio bíblico en donde todo el poema es una acción de gracias, pues escenifican la posición de un creyente que testifica el poder salvador de Dios y la manifestación de su amor (Mannati 1979: 21). Por ejemplo, el último salmo, el 150 es un verdadero canto de alabanza. Se trata de un himno en su sentido estricto por cuanto se asocia "la manifestación del poder de Dios y la manifestación de su amor" (Mannati 1979: 21); se trata de una invitación a la alabanza y a la acción de gracias dentro de un marco cultural, que reúne a todos los instrumentos musicales conocidos en tiempos del rey David:

\section{¡Aleluya!}

Alabad a Yavé en su santuario, alabadlo en su augusto firmamento, alabadlo por sus grandes maravillas, alabadlo por su inmensa majestad.

Alabadlo con clangor de corneta, alabadlo con danza y con tambor, alabadlo con cuerdas y con flautas, alabadlo con címbalos sonoros, alabadlo con címbalos triunfantes. ¡Todo cuanto respira alabe a Yavé!

¡Aleluya! (Santa Biblia, 1976: 745)

Es un himno final de alabanza de la creación toda entera y desemboca en la entrada triunfal del tabernáculo, cuando desde allí se expande hacia el "firmamento" el gran concierto universal. Los instrumentos musicales de viento y de percusión, además de aquellos que se percuten ("cítara" y "arpa") 
están al servicio de la alabanza lograda cuando el regocijo y la celebración se dan de la mano en el ritual de agradecimiento, porque incluye la "danza". Ello no es inocente en la poesía hímnica, que desde la Antigüedad grecolatina remite al espectáculo convocado por la danza, el mimo y la música para expandir en el aire la proclama de esa manifestación de la divinidad. De esta manera, música y palabra en tanto voz que actualiza, proyectan esa presencia que el yo lírico, oficiante en el ritual de alabanza, sabe reconocer. Por eso de la regularidad y la simetría de la versión bíblica, la tipografía, la fragmentación, la dislocación de los versos y la ausencia de puntuación en tanto recursos expresivos, hace que el universo en expansión y en movimiento, en el "Salmo 150" cardenaliano se identifique, es cierto, también con ese poder creador de la divinidad, pero en Cardenal obedece en esa maravillosa perplejidad de la voz poética ante la energía cósmica creadora que fluye en un devenir infinito; el "cientificismo" de Ernesto Cardenal se manifiesta en términos físicomatemáticos (Burdiel de las Heras, 1982: 211):

Alabad al Señor en el cosmos

Su santuario

de un radio de 100.000 millones de años luz Alabadle por las estrellas y los espacios inter-estelares alabadle por las galaxias y los espacios inter-galáxicos

alabadle por los átomos y los vacíos inter-atómicos

(Cardenal 1991: 182)

Este carácter etéreo, radiante, reactivo, lumínico del inicio del "Salmo 150" describe la potencia y la irradiación de una creación universal que desplaza al ser humano; la altura y la expansión de esta proyección del cosmos intensifica los decibeles de la alabanza hacia su expansión galática; la misma disposición tipográfica de los versos ayuda, en su tipografía, a una desarticulación de repliegue/ expansión de la imagen visual (Martínez, 1996: 110). Como en el Salmo bíblico, la alabanza comienza en el "cosmos", con el movimiento lumínico de "años luz", en una irradiación que atañe tanto a "estrellas" y "galaxias" (en dilatación) como a los "átomos", para que el fluir y el movimiento lo envuelva todo en una especie de "Exultate, jubilate". Por eso, la alabanza (la palabra poética) da paso al concierto de instrumentos, que como expresión hímnica elevada a la última potencia, constituyen el canto poético. El crescendo y el movimiento ascensional, que se traduce en la construcción del poema gracias a la dislocación y a la fragmentación; dan cuenta de esta expansión del sonido:

Alabadle con el violín y la flauta y con el saxofón

alabadle con los clarinetes y el corno con cornetas y trombones con cornetines y trompetas

alabadle con violas y violoncelos con pianos y pianolas

alabadle con blues y jazz

y con orquestas sinfónicas

con los espirituales de los negros y la $5^{\text {a }}$ de Beethoven

con guitarras y marimbas

alabadle con toca-discos

y cintas magnetofónicas

Todo lo que respira alabe al Señor toda célula viva Aleluya (Cardenal 1991: 182)

No solo la construcción tipográfica del poema da cuenta de ese ritmo ascensional propio de la espiral; también la enumeración de los instrumentos musicales en series y en afinidad por su timbre y su forma de ejecución culminan en una apoteosis de sonidos, que Cardenal sabe acentuar en la escogencia de "los espirituales" y de la Quinta Sinfonía de Ludwig van Beethoven. Los instrumentos musicales se multiplican en la versión cardenaliana y se amplían a otras formas corales y grupales, de modo que lo colectivo se refuerza en el sonido aumentado de coros y orquestas. Se funden en un sonido colorido y amplificado sin igual. Se está ante la presencia, en los dos últimos salmos de Cardenal, de una poesía transformadora y transformada, cuya combinación de imágenes visuales y auditivas obligan a que el espacio poético 
se dilate y se amplifique (Pérez 2001: 101). Pero la referencia a la Quinta Sinfonía de Ludwig van Beethoven no es inocente, porque con ella se llega a un clímax radiante y apoteósico en donde como, himno de la alegría, la celebración musical llega a su paroxismo. Si hubiera que buscar su transposición musical, sería el principio del cuarto movimiento de la Quinta sinfonía, en cuyo "allegro" se precipita toda la orquesta con staccato $^{8}$ en un torbellino que crece y se precipita hacia una alabanza universal y cósmica en Ernesto Cardenal, para que vuelva a cerrarse sobre la medida de lo humano.

\section{La canción y el embelesamiento de los trovadores medievales: Fánor Tellez}

Por su parte, en Oficio de amarte (1999), Fánor Téllez invita a un movimiento en el que el yo lírico inicia un doble periplo, existencial y sentimental, como búsqueda de un nuevo entendimiento de la pareja, y ensaya un discurso amoroso cargado de reminiscencias a la tradición primitiva de la lírica occidental. El análisis se centrará en la sección segunda de su poemario, cuyo título es "La canción por ti encendida", con una reminiscencia al libropoema del español Pedro Salinas, La voz a ti debida (1933); en Salinas hay una búsqueda del tú amoroso femenino, al recrear esa necesidad de una completud solamente alcanzable en la evocación de la ausencia. Salinas no solo se interroga por la materialidad misma del material verbal de la poesía en tanto música, sino también por la capacidad de ese medio para expresar realidades tales como la amada, a quien en el principio del poema tiene el atributo de poseer "la vida", en equiparación con la "música":
Tú vives siempre en tus actos.

Con la punta de tus dedos

pulsas el mundo, le arrancas

auroras, triunfos, colores,

alegrías: es tu música.

La vida es lo que tú tocas. (Salinas, 1974: 49, vv. 1-6)

Como indican los versos, la amada posee el arte de "pulsar" las cuerdas de la vida y, por lo tanto, de dominar el arte del amor y de la vida. Recrear esa voz universal y cósmica es lo que pretende Salinas por medio de la amada ausente. Eso es lo que también realiza Fánor Téllez en Oficio de amarte, en homenaje consciente a la lírica trovadoresca en la que la asociación entre Poesía y Música se despliega. La portada del poemario recuerda que los juglares o trovadores acompañaban sus poemas amorosos al son de instrumentos musicales, tales como cítaras, laúdes o flautas; la portada acoge un motivo medieval, en donde una pareja, hombre y mujer, aparece tocando sendos instrumentos, el laúd y la cítara. Así, Fánor Téllez convoca en Oficio de amarte el marco refinado del discurso amoroso de los trovadores y de las cortes y palacios medievales.

Interesa el segundo poema de esta sección con el título metagenérico de "Trova". Alude al arte propio del componer y del ejecutar poemas. Si la Poesía es, ante todo, música puesta en palabras, voz en acorde con música, Téllez invita a que el lector se interese en el carácter elusivo y metafórico de la palabra poética, más propensa a sugerir y a mover las pasiones del alma a través de esa seducción/ captación de lo sensorial y de lo intuitivo.

\footnotetext{
${ }^{8}$ Indica la sucesión de notas rápidas que deben destacarse cada una.
} 
Lleva el trovador canciones, lleva su oficio, su atavío de palabras,

el compañero instrumento de cuerdas a la sala

en que afina su voz conforme la corriente de tu sangre

o los cambiantes matices de tu piel

o la cromática graciosa de tu risa

y tus ojos dejan de atender a su señor para tender otra mirada a quien cadencia

cantos de buen amor en tu presencia como si fueran trovas para distinta dama

y no se intrigue el anfitrión de verlo inclinado a tu figura. (Téllez, 1999: 20)

Al ejercicio de laúd, voz y poesía se le denomina el arte de la "trova", lo cual se evidencia en el genérico de "canciones" y se alude en relación metapoética, al arte de componerlas; al son del "compañero instrumento de cuerdas". Refiere también al espacio comunicativo en donde se situaba este tipo de composiciones poéticas, la "sala" del palacio en tanto lugar abierto y público, nunca uno reservado o privado porque la ejecución

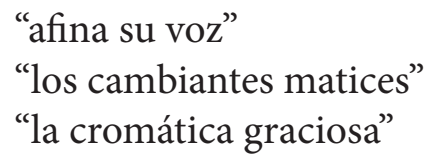

Por eso, toda la dinámica de "tus ojos" se vuelca hacia "otra mirada" en esa reciprocidad buscada en un juego furtivo, de correspondencias sublimadas. La correspondencia de este amor es imposible en la medida en que la dama le pertenece a otro, de manera que las "canciones" del trovador son un medio metafórico para establecer el contacto amoroso a distancia; la poesía se transforma en el canal y el código de una comunicación erótica establecida con la musicalidad y sensualidad del trovar. Se trata de un mimetismo entre "el instrumento de cuerdas" y las sensaciones despertadas en la dama. Aquí el laúd pasa a ser una nueva sinécdoque de la amada, y "su oficio", el cual es ejecutar el instrumento, modular su voz y cantar esas palabras que seducen y enamoran por su contenido sublime y delicioso, tensan la relación dentro de un desenfreno y de un placer contagiante de una escritura poética, transformada también en seducción musical. De esta manera, instrumento y objeto amoroso se confunden y se hace ante la corte y a la vista del señor, a quien el "trovador" presta su servicio. Su señora, la dama, se transparenta en el "tú" al que se dirige la comunicación poética-música. Esas "canciones" se establecen como la mediación entre ellos; es precisamente la poesía/música que los une en una reciprocidad establecida por el poema a través de esa disposición de la amada al "trovar", a la ejecución:

$\rightarrow \quad$ "la corriente de tu sangre"
$\rightarrow \quad$ "tu piel"
$\rightarrow \quad$ "tu risa"

el trovador ejerce su ars amatoria y, con el poder simbólico concedido por la Poesía, neutraliza esa distancia para que ocurra una metamorfosis en dos movimientos:

a)Transmuta su laúd en el cuerpo de la amada, de ahí las equivalencias que se explicitan en los versos 3 a 5: "la corriente de tu sangre" $\rightarrow$ "los matices cambiantes de tu piel" $\rightarrow$ "la cromática graciosa de tu risa”. b) En una relación de complementariedad y de sincronía, propio de una somatización de la retórica amorosa, el trovador ejecuta su instrumento al ritmo de los sentimientos y a las fluctuaciones de su amada.

En la poesía trovadoresca, la pasión amorosa es tan intensa que prueba los valores cortesanos del servicio y vasallaje: la virtud, el honor, la entrega total y la generosidad al servicio de la dama, en un doble juego que involucra el merecimiento o la desesperación del "servidor de amor" frente a la 
dama (Rey Hazas, 1981: 69-70). El poeta- trovador debe hacerse acreedor, es decir, debe merecer el amor de su dama y su oficio y su virtuosismo poético debían estar consagrados a este propósito. Las convenciones del amor cortés aparecen, en primer lugar, con la aparición de la figura de la dama cortesana, una nueva "deidad plenamente antropomórfica y secular” (Gerli 1981: 69). Michael E. Gerli ha estudiado las transformaciones que, en la lírica castellana, se producen en la idealización de la dama como suplantación antropomórfica y secular de la Virgen María y plantea que la dama viene a integrar "todos los ideales del amante y reparte el don de la salvación [...], es el foco de veneración, contemplación y meditación" (1981: 76). Pero también la separación de los amantes se debe a impedimentos de índole social que responden a estamentos distintos de la estática sociedad medieval. En el poema de Téllez, entre dama y trovador solamente puedan establecer un juego de miradas cómplices pero furtivas.
El tiempo del amor cortés evoca una concepción del trabajo de la teckné poética en la que la voz acompasada del juglar/poeta se exhibe y se manifiesta; las frases de la "canción" debían poseer una "construction rythmique similaire" (Les très riches heures du Moyen Age, 1995: 46), pero Téllez no respeta ni las estructuras estróficas ni rítmicas de las composiciones que se encuentran en los cancioneros de palacio. Su poema se compone, más bien, de frases que tienden a una duración más larga y rítmica. En este contexto, la poesía es ejercicio, es decir, pulimento y esfuerzo dedicado para componer poemas y toda la ejecución está al servicio del efecto logrado, de una frase alambicada y de sintaxis compleja, en la que se esconde su sentimiento y su mirada ("como si fueran trovas para distinta dama/ y no se intrigue el anfitrión de verlo inclinado a tu figura"). De manera que la sintaxis compleja y los versos largos sirven para tender puentes y escenificar la simulación de los verdaderos afectos, como lo recuerda el yo poético observador en la segunda parte del poema:

Pero tú sabes para quién son sonidos, ritmos, pausas

y su decir amable del deseo,

esa gracia de llamar a un cuerpo con galante

y febril insinuación,

porque cuando en negocios ausente tu señor de ti se olvida,

discreta,

y presurosa, alcanzas tiempo, lecho, la manera más oculta

de poner seda y rosa, perfume

y labio de fuego sobre la boca que te ha cantado con pasión muy

refinada.

(Téllez, 1999: 20)

El homenaje se vuelve ruptura, lo cual contribuye a la renovar la tradición del amor cortés, cuando dentro de la oposición "negocios"ocio, se neutralizan los obstáculos posibles para la consumación erótica. La referencia metagenérica surge en la enumeración "sonidos, ritmos, pausas/ y su decir amable del deseo", porque es consciente Fánor Téllez que la poesía/música no solo ablanda los corazones sino también acerca las distancias irresolubles. Por medio del "trovar" los impedimentos se desmoronan y los afectos se encarecen; de ahí las dos sinécdoques utilizadas para convocar ese dulce y embrujante canto: "su decir amable del deseo,/ esa gracia de llamar a un cuerpo con galante/ y febril insinuación". El tópico del furor amoris de nuestra retórica amorosa surge al final, cuando en esa correspondencia de miradas y reciprocidad de afectos, se sella todo con "perfume/ y labio de fuego sobre la boca", sinécdoque del beso y de la unión fortuita de los amantes, quienes han derribado los muros expugnables del decoro social, porque termina con la entrega real y no solo espiritual. 


\section{Conclusiones}

Para algunos críticos, la tesis de que el poema es una construcción conduce a subrayar la construcción-modelación de un volumen arquitectónico o musical, gracias precisamente al valor eufónico de las estructuras rítmicas y métricas en un poema (Hidalgo, 1999: 145); la plasticidad se logra en esa convocatoria de lo cromático-visual, lo auditivo-melodioso y lo tactil-sensorial dentro de un efecto compositivo-estructural propio de lo estético. Según Narciso J. Hidalgo, plantear una arquitectura poética supone considerar que el ritmo y la musicalidad del lenguaje poético "se articulan o desarticulan por el sonido, al margen de su representación gráfica" (1999: 146); sin embargo, reducido a lo eufónico la clave del volumen poético implicaría dejar por el fuera la representación visual o tactil que lo acompaña y, principalmente, el diseño compositivo del texto.

No solo se trata de sentir, ver, palpar, oír o gustar por medio, gracias o con las palabras, sino que el lenguaje poético, en tanto experiencia estética, convoca la alusión, la asociación y la sugerencia, propio del nivel connotativo y de la función emotiva del lenguaje, para que las referencias intersemióticas surjan. Lo anterior es necesario para captar el grado de intertextualidad desplegado por este tipo de poesía. Si la intertextualidad se define, en primer lugar, como esa percepción que el lector puede establecer entre un texto y otros que le han precedido o le son sincrónicos (Riffaterre, 1980: 4), el establecimiento de esas relaciones debe permitirse por recursos textuales, a veces perceptibles y buscados, otras veces menos evidentes pero que funcionan hasta que son identificados9. Los trazos de la intertextualidad, prosigue Riffaterre, se circunscriben a procedimientos estilísticos, regulados por imperativos textuales, con el fin de que los mecanismos de percepción-identificación se desencadenen; uno de ellos sería, en este caso, las correspondencias con la Música, que el lector avezado recrea en su mente cuando lee los poemas analizados.

\footnotetext{
${ }^{9}$ En este caso, Riffaterre habla de fenómenos de intertextualidad aleatoria, porque dependen del reconocimiento por parte del lector para captar toda su dinámica y su interpretación: "La perception est donc aléatoire, puisqu’elle nécessite un certain dégré de culture, des lectures préalables" (Riffaterre, 1980: 5), con lo cual comprende que las citaciones, alusiones literarias, motivos y temas sean perceptibles e identificables.
} 


\section{Bibliografía}

Abrams, M. H. (s. f.). El espejo y la lámpara: Teoría romántica y tradición clásica acerca del hecho literario. Buenos Aires: Editorial Nova.

Aguiar e Silva, Vítor Manuel. (1979). Teoría de la literatura. Madrid: Editorial Gredos, 3a. reimpresión.

Alighieri, Dante. (1914). La divina comedia, commentata da G. A. Scartazzini. Milán: Editore-Libraio Della Real Casa.

Alonso, Amado. (1969). Materia y forma en poesía. Madrid: Editorial Gredos, 3a. edición, 1969.

Argüello Lacayo, José. (2004). Prólogo. Los místicos Caminos del poeta andariego. Azarías H. Pallais. Caminos. Managua: Hispamer, 9-20.

Béguin, Albert. (1993). El alma romántica y el sueño: Ensayo sobre el romanticismo alemán y la poesía francesa. Madrid: Fondo de Cultura Económica, 2a. reimpresión.

Burdiel de las Heras, María C. (1982). La literatura científica y Las galaxias cantan la gloria de Dios. Letras 10: 207-221.

Cardenal, Ernesto (1991). La noche iluminadora de palabras. Obras completas. Tomo I. Managua: Ediciones Nicarao.

Cañas Quirós, Roberto. (1995). La poesía en Platón (I Parte). Revista de Filosofía de la Universidad de Costa Rica 33.80: 79-85.

García Berrio, Antonio. (1973). Significado actual del formalismo ruso (La doctrina de la Escuela del método formal ante la poética y la lingüistica modernas). Barcelona: Editorial Planeta.

Gerli, Michael E. (1981). La "Religión de Amor" y el antifeminismo en las letras castellanas del siglo XV. Hispanic Review 49. 1: 65-86.
Hidalgo, Narciso H. (1999). Arquitectura rítmica y son en Los motivos del son. Monographic Review/ Revista Monográfica 15: 145-160.

Kerkhoff, Manfred. (1997). Kairós: Exploraciones ocasionales en torno a tiempo y destiempo. Río Piedras: Editorial de la Universidad de Puerto Rico.

Mannati, Mariana. (1979). Orar con los salmos. Estella (Navarra): Editorial Verbo Divino, 2. edición.

Martínez Fernández, José Enrique. (1996). El fragmentarismo poético contemporáneo (Fundamentos teórico-críticos). León: Servicio de Publicaciones de la Universidad.

Pallais, Azarías H. (2004). Caminos. Managua: Hispamer.

Pérez Martín, Norma. (2001). Lirismo reflexivo y estética de la transfiguración en el Tránsito de fuego. La palabra innumerable: Eunice Odio ante la crítica. Jorge Chen Sham y Rima de Vallbona (Eds.). San José: Editorial de la Universidad de Costa Rica/ Instituto Literario y Cultural Hispánico: 97-119.

Platón. (1974). Ion. Buenos Aires: Editorial Universitaria.

—. (2004). Fedón/ Fedro. Madrid: Mestas Ediciones.

Promis Ojeda, José. (1975). Espíritu y Materia: Los Salmos de Ernesto Cardenal. Ernesto Cardenal: poeta de la liberación latinoamericana. Buenos Aires: Fernando García Cambeiro Editor, 15-38.

Rey Hazas, Antonio. (1982). Introducción a la novela del Siglo de Oro, I (Formas de narración idealista. Edad de Oro 1: 65-105.

Riffaterre, Michael (1980). La trace de l'inertexte. La Pensée 215: 4-18. 
Risley, William R. (1992). Hacia el simbolismo en la prosa de Valle-Inclán. Johnn Gabriele (Ed.). Suma valleinclaniana. Barcelona: Editorial Anthropos, 53-95.

Salinas, Pedro. (1974). La voz a ti debida. Razón de amor. Madrid: Editorial Castalia, 2a ${ }^{\text {a }}$ edición.

Santa Biblia, La. Madrid: Ediciones Paulinas, 1976.

Schaeffer, Jean-Marie. (1980). Romantisme et langage poétique. Poétique 42: 177-194.

Téllez, Fánor (1999). Oficio de amarte. Managua: Centro Nicaragüense de Escritores.

Très riches heures du Moyen Age, Les (1994). Arles: Harmonia Mundi France.

Wellek, René y Austin Warren. (1979). Teoría literaria. Madrid: Editorial Gredos, $3^{\text {a }}$. reimpresión. 